\title{
Study on Vibration Suppression Control for Rotary Compressor
}

\author{
Yasuo Notohara ${ }^{* a)}$ Member, \\ Dongsheng $\mathrm{Li}^{*}$ \\ Non-member \\ Yoshitaka Iwaji $^{* *}$ \\ Senior Member, \\ Masahiro Tamura** \\ Non-member \\ Koji Tsukii ${ }^{* * *}$ Member
}

J-STAGE Advance published date : March 19, 2021

\begin{abstract}
Recently, permanent magnet synchronous motor (PMSM) drive systems without the rotor position sensor are widely used as actuators in many applications. However, in the case of a pulsating load such as the compressors, the rotational speed of the motors is fluctuated and the drive system is vibrated due to the pulsating load torque. In this paper, we propose a new method to reduce the rotational speed pulsation. This method can seamlessly change the vibration suppression control and the high efficiency control. The simulation results indicate that the proposed method is very effective and practical.
\end{abstract}

Keywords: rotary compressor, vibration suppression, high efficiency, seamless

\section{Introduction}

Inverters have increasingly been incorporated in motor drive devices in recent years. Among these, the permanent magnet synchronous motor has high efficiency compared to induction motors, so most household appliances have become inverter drive devices which use a permanent magnet synchronous motor. These devices have also been driven by sine waves with the objective of improving their efficiency and noise reduction ${ }^{(1)}$.

Therefore, driving the permanent magnet synchronous motor with sine waves at a high level of performance requires accurate detection of the rotor position, but methods which use high-resolution position sensors or motor current sensors are expensive and difficult to apply in household appliances. There has thus been progress in the development of sensorless control methods which do not use such expensive motor current sensors or position sensors, and these have currently been applied to various household appliances.

The authors have also proposed a motor current sensorless/position sensor-less sine wave vector control method that reproduces the motor current from the DC bus current (less $\&$ less method) ${ }^{(2)-(4)}$. Furthermore, the cascade vector control method ${ }^{(5)}$ which serves as the basis for this vector control uses the extended induced voltage method ${ }^{(6)}$ to achieve sensor-less control, as well as combines the inverse model of the $d-q$ axis interference term of the motor with current control to achieve ideal current control characteristics. Stable

a) Correspondence to: Yasuo Notohara. E-mail: yasuo.notohara. ss@hitachi.com

* Research \& Development Group, Hitachi, Ltd.

7-1-1, Omika-cho, Hitachi, Ibaraki 319-1292, Japan

** Graduate School of Science and Engineering, Ibakaki University

4-12-1, Nakanarusawa-cho, Hitachi, Ibaraki 316-8511, Japan

*** Hitachi-Johnson Controls Air Conditioning, Inc. 500, Tomita, Ohira-machi, Tochigi, Tochigi 329-4404, Japan current control even under low-period calculations is a feature of this method.

Meanwhile, there have been investigations on reducing the compressor rotational speed in devices which use cooling cycles (e.g., air conditioners, refrigerators) in order to save energy and reduce noise. However, the rotary compressor has periodic fluctuations in load torque (periodic torque disturbance) due to the suction of refrigerants and the compression stroke. Vibrations are generated according to differences from the motor output torque, so this hampers further decreases in the compressor rotational speed.

Various countermeasures have been proposed against such periodic torque resistance, including a method which sets the output torque pattern of the motor in advance, reads out the output torque patterns according to the rotational speed or average torque, and controls the motor output torque; or methods which control the motor output torque by introducing repeated control or Fourier transformations ${ }^{(7)-(12)}$. The authors have also used the square wave drive method to propose a periodic torque resistance suppression control which uses repeated control and applied this to compressor drive devices for room air conditioners ${ }^{(13)-(16)}$.

A periodic torque resistance suppression control has also been previously proposed in the sine wave vector control $\operatorname{method}^{(17)}$. This method estimates the pulsating component of the torque from the axis error estimated value, which is the error between the control axis and the actual axis. This estimated value is then compensated with a periodic torque resistance compensator which uses simple Fourier transforms and inverse transforms to match the load torque and motor output torque, suppressing the vibrations caused by load torque fluctuations.

As described above, vibration suppression control suppresses rotational speed fluctuations and reduces compressor vibration by matching the load torque and motor output torque. However, system efficiency decreases because the peak motor current value fluctuates greatly according to the 
motor output torque.

Therefore, methods which increase vibration by controlling the motor output torque to a constant level according to the air conditioning operation conditions, but which increase system efficiency by setting the peak motor current value as a constant have been used ${ }^{(18)}$.

This article proposes a vibration suppression control which suppresses the rotational speed fluctuations due to periodic torque resistance by using a controller that uses sine wave transfer functions (referred to as an S controller) ${ }^{(19)(20)}$, as well as a control configuration which can seamlessly change highefficiency control which increases system efficiency by maintaining the motor output torque at a constant level (referred to as seamless torque control).

Specifically, we introduce a motor drive system for air conditioners, and report on vibration suppression effects from simulation results and actual devices after explaining the system torque control configuration and the $\mathrm{S}$ controller.

\section{Motor Drive System for Air Conditioners}

2.1 Outline of Motor Drive System Figure 1 shows a simplified configuration diagram of the motor drive system. The motor drive system for air conditioners is primarily composed of a diode rectifier, smoothing capacitor and inverter, and a control micro-computer. Furthermore, a one-shunt current detection method which reproduced a three-phase motor current from the DC bus current was used for reducing costs. A high-efficiency permanent magnet synchronous motor (PMSM) was also used for the motor.

2.2 Position Sensor-less/Motor Current Sensor-less Cascade Vector Control Figure 2 shows a block diagram of the motor control. A position sensor-less control that used extended induced voltage ${ }^{(6)}$ was adopted in order to drive the motor that was built inside the compressor, and

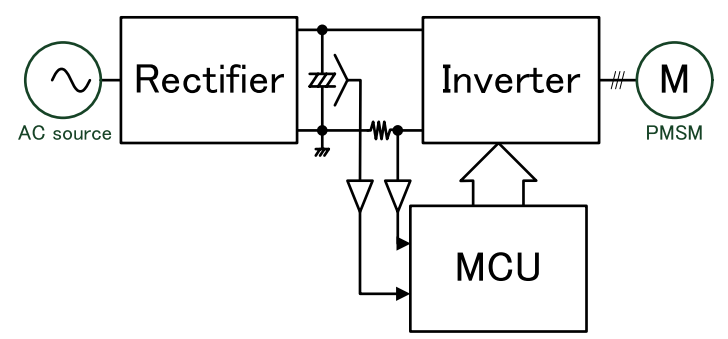

Fig. 1. Drive system used in air-conditioner this is a method which uses PLL to adjust the speed $\omega_{\mathrm{r}}$ so that the axis error $\Delta \theta$ would be zero.

The current control (ACR) also adopts the previously proposed cascade vector control ${ }^{(5)}$. Using this control enables a stable current control without setting the ACR calculation cycle early.

The currently proposed seamless torque control is achieved by adding to the speed control (ASR) configuration. Details of the seamless torque control are explained below.

\section{Seamless Torque Control}

3.1 Overall Configuration Figure 3 shows a block diagram of seamless torque control. $\mathrm{S}$ controller 1 is a vibration suppression controller which outputs the pulsating torque current command Iqsin* so that the frequency component of the periodic torque resistance included in the rotational speed deviation $\Delta \omega_{\mathrm{r}}$ would be zero, from which the period disturbance torque and motor output torque are matched to suppress vibration.

$\mathrm{S}$ controller 2 is a high-efficiency controller which outputs the speed deviation correction value $\Delta \omega_{\text {rsin }}{ }^{*}$ so that the frequency component of the periodic torque resistance included in the torque current command $\mathrm{Iq}_{0}{ }^{*}$ output from ASR is zero, after which the SDR speed deviation $\Delta \omega_{\mathrm{r} 0}$ is corrected to control the peak motor current value to a constant value and reduce conduction loss.

As shown in Fig. 3, S controller 1 (vibration suppression

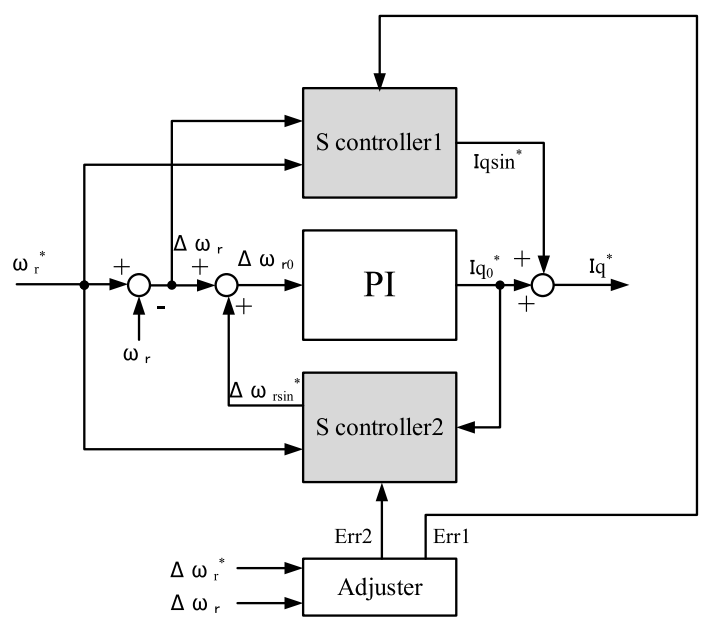

Fig. 3. Proposed seamless torque control configuration

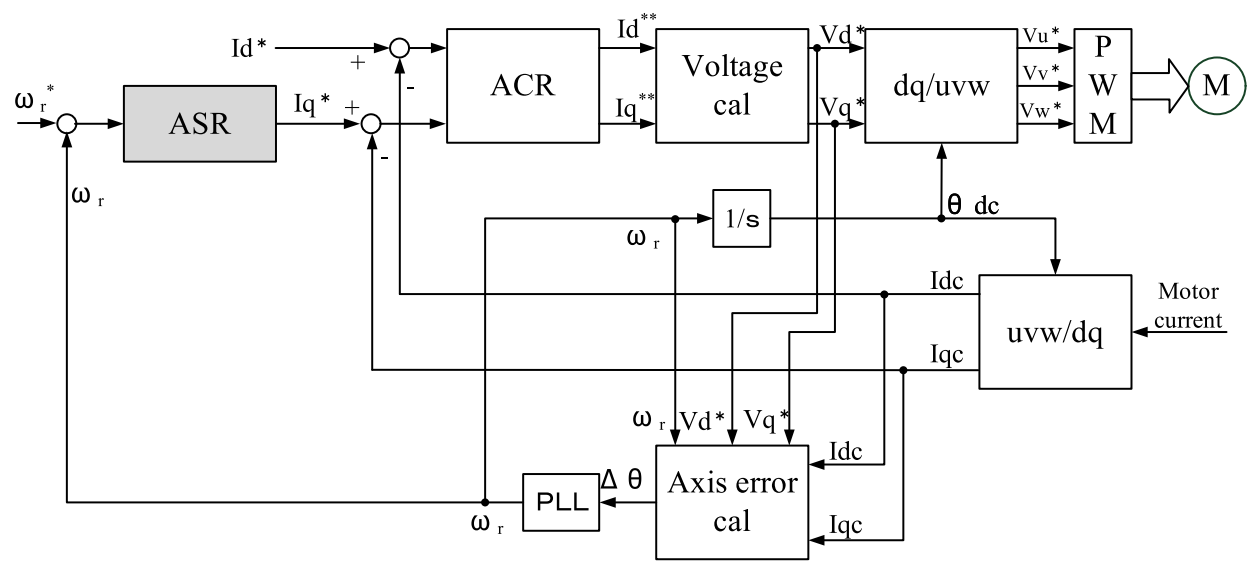

Fig. 2. Motor control configuration used in air-conditioner 
controller) was connected to ASR in parallel, and $\mathrm{S}$ controller 2 (high-efficiency controller) is connected in antiparallel.

Here, there is an adjustment method for calculating the $S$ controller error value $\mathrm{E}_{\mathrm{rr}}$ by using the rotational speed fluctuation width command value $\Delta \omega_{\mathrm{r}}{ }^{*}$ in order to adjust the effectiveness of the vibration suppression and high-efficiency control.

Figure 4 shows a block diagram of the adjustment method. This adjustment method calculates the error value $\mathrm{E}_{\mathrm{rr}}$ by using the integral control from the deviation between the rotational speed fluctuation width command value $\Delta \omega_{\mathrm{r}}{ }^{*}$ and amplitude of the rotational speed fluctuation value $\Delta \omega_{\mathrm{r}}$.

The error value $E_{\mathrm{rr} 1}$ is input into $S$ controller whereas $E_{\mathrm{rr} 2}$ $\left(=1-\mathrm{E}_{\mathrm{rr} 1}\right)$ is input into $\mathrm{S}$ controller 2 so that the effectiveness of $\mathrm{S}$ controller 1 (vibration suppression controller) and S controller 2 (high-efficiency controller) are opposite. Here, the rotational speed fluctuation width command value $\Delta \omega_{\mathrm{r}}{ }^{*}$, integral gain $\mathrm{K}$, and the $\mathrm{S}$ controller control gain $\mathrm{K}_{\mathrm{s}}$ (discussed later) were determined with air conditioner system experiments.

3.2 Outline of Seamless Torque Control Operation

Figure 5 shows an image of the seamless torque operation. This figure is an image of the rotational speed fluctuation width command value $\Delta \omega_{\mathrm{r}}{ }^{*}$ operation, with the rotational speed on the horizontal axis and the rotational speed when the rotational speed fluctuation width command value $\Delta \omega_{\mathrm{r}}^{*}$ was taken on the vertical axis.

As shown in this figure, the low-speed region (below $1500 \mathrm{~min}^{-1}$ ) switches to the vibration suppression control, the moderate speed region $\left(3000 \mathrm{~min}^{-1}\right.$ to $4500 \mathrm{~min}^{-1}$ ) switches to the high-efficiency control, and the high-speed region (over $4500 \mathrm{~min}^{-1}$ ) switches to the normal control.

Here, vibrations due to periodic torque resistance also decrease in the intermediate region between the low speed and moderate speed regions (1500 $\mathrm{min}^{-1}$ to $3000 \mathrm{~min}^{-1}$ ), so the need for complete vibration suppression control also decreases. In other words, operations which increase efficiency

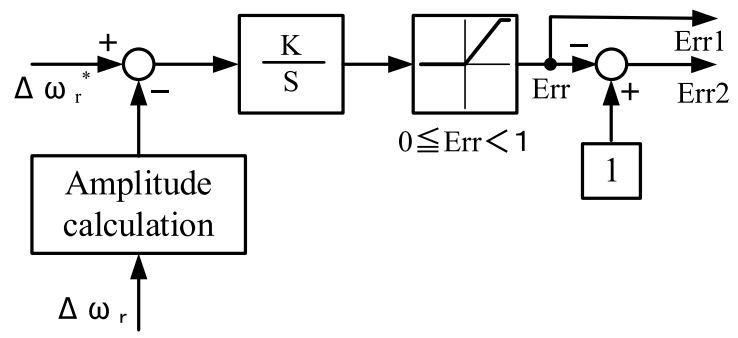

Fig. 4. Block diagram of the adjuster while suppressing vibration are desired.

Therefore, it is decided that this region is operated using seamless torque control (i.e., change the rotational speed fluctuation width command value $\Delta \omega_{\mathrm{r}}{ }^{*}$ ).

3.3 S Controller The $\mathrm{S}$ controller uses the transfer function of Eq. (1) and has the feature of having an extremely large gain with respect to a specified frequency $\left(\omega_{0}\right)$.

$$
G_{c}(s)=K_{s} \frac{s}{s^{2}+T_{a} s+\omega_{0}^{2}}
$$

Here, $K_{s}$ is the control gain, $T_{a}$ is the damping constant, and $\omega_{0}$ is the central frequency. The rotational speed command $\omega_{\mathrm{r}}^{*}$ is set when $\omega_{0}$ is this control.

Here, the damping constant $\mathrm{T}_{\mathrm{a}}$ is as shown in Eq. (2).

$$
T_{a}=K_{s}\left\{\frac{E_{r r}}{\left(1-E_{r r}\right)}\right\}
$$

The damping constant $T_{a}$ is calculated as shown in Eq. (2). As shown in Fig. 4, the effectiveness of the $\mathrm{S}$ controller was also adjusted by calculating the $\mathrm{E}_{\mathrm{rr}}$ value.

Figure 6 shows an example of a Bode diagram of the $S$ controller $\left(\mathrm{K}_{\mathrm{s}}=314 \mathrm{rad} / \mathrm{s}, \mathrm{T}_{\mathrm{a}}=0, \omega_{0}=100 \mathrm{~Hz}\right)$. Figure 7 shows a block diagram of the $\mathrm{S}$ controller.
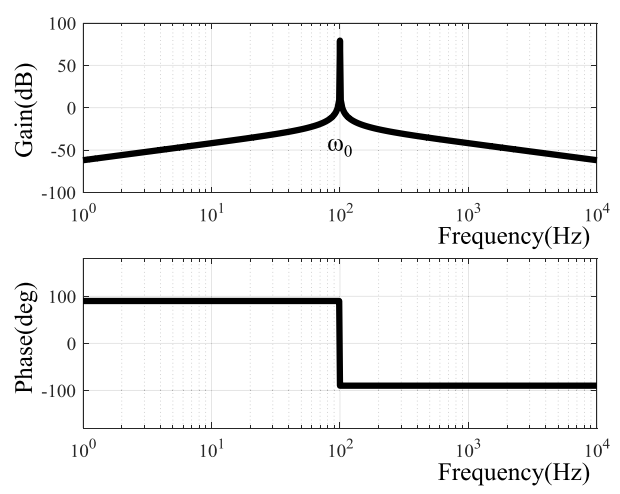

Fig. 6. Bode diagram of S controller

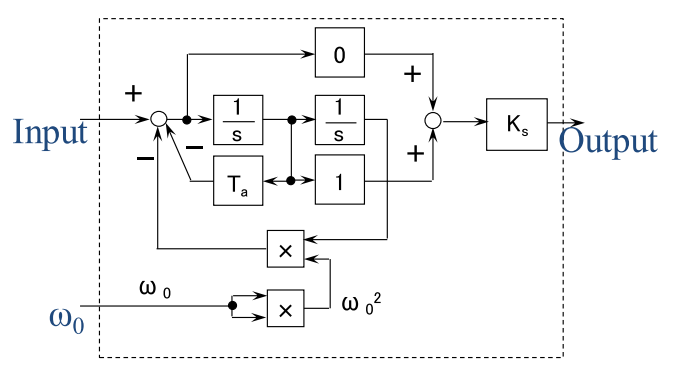

Fig. 7. Block diagram of S controller

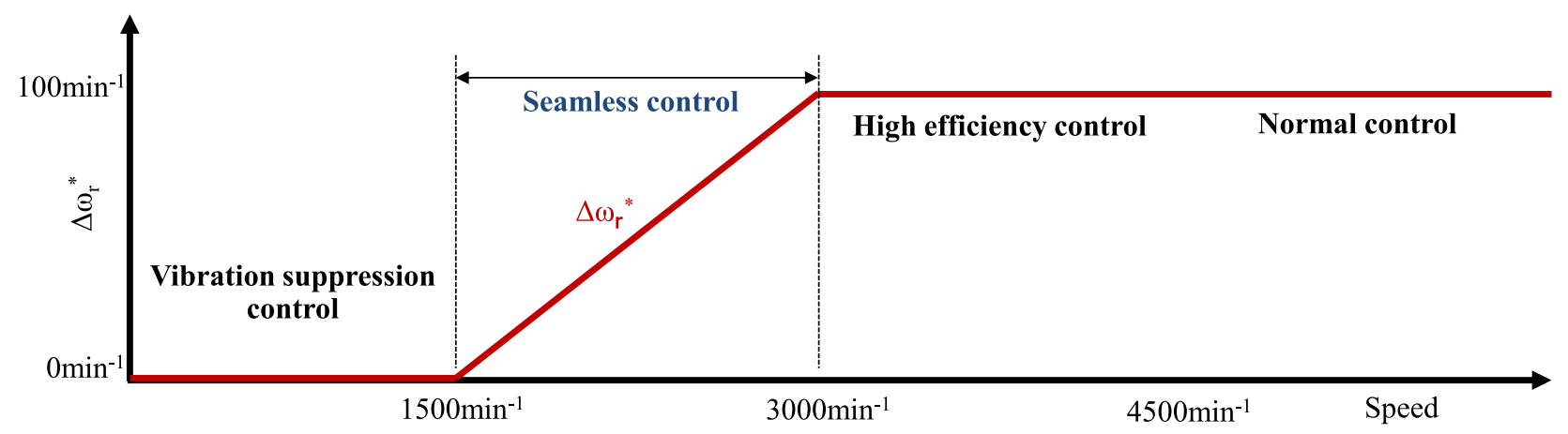

Fig. 5. Image of operation of seamless torque control 


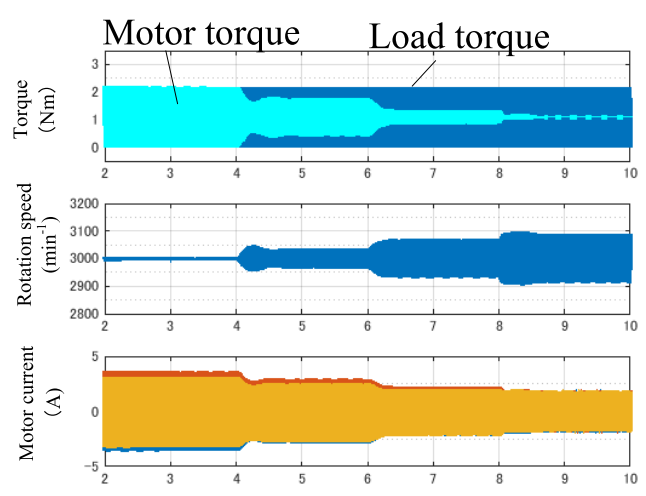

Fig. 8. Simulation waveform for seamless torque control at $3000 \mathrm{~min}^{-1}$
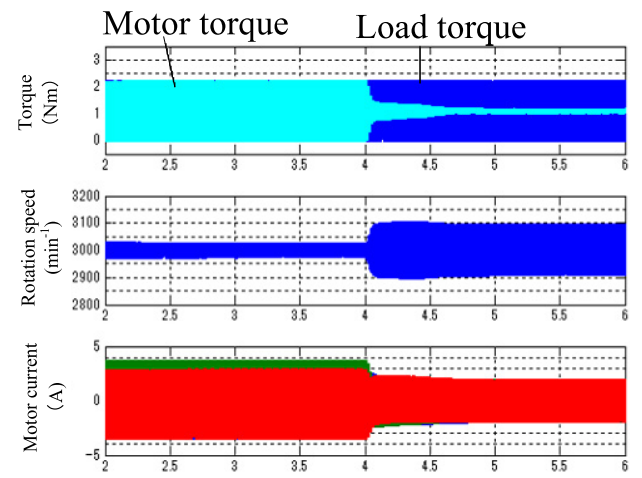

Fig. 9. Simulation waveform of seamless torque control at $3000 \mathrm{~min}^{-1}$ (sudden change)

\section{Simulation Results}

4.1 Overall Waveform Figure 8 shows the overall waveform of the torque, rotational speed, and motor current when the effectiveness of the vibration suppression control was changed in four stages. The rotational speed command $\omega_{\mathrm{r}}^{*}$ was $3000 \mathrm{~min}^{-1}$. The waveforms shown are the load torque and motor output torque, rotational speed, and motor current (three-phase), from top to bottom.

Time $2 \mathrm{~s}-4 \mathrm{~s}$ shows the operation waveform at a vibration suppression control of $100 \%$ (rotational speed fluctuation width command value $\left.\Delta \omega_{\mathrm{r}}{ }^{*}=0 \mathrm{~min}^{-1}\right)$, and time $8 \mathrm{~s}-10 \mathrm{~s}$ shows the operation waveform at a high-efficiency control of $100 \%$ (rotational speed fluctuation width command value $\left.\Delta \omega_{\mathrm{r}}{ }^{*}=300 \mathrm{~min}^{-1}\right)$. The intermediate times of $4 \mathrm{~s}-6 \mathrm{~s}$ and $6 \mathrm{~s}-8 \mathrm{~s}$ show the operation waveforms with rotational speed fluctuation width command value $\Delta \omega_{\mathrm{r}}{ }^{*}=40 \mathrm{~min}^{-1}$ and rotational speed fluctuation command value $\Delta \omega_{\mathrm{r}}{ }^{*}=70 \mathrm{~min}^{-1}$, respectively.

Figure 9 also shows the operation waveform when rapidly changed from the vibration suppression control to the highefficiency control (rotational speed fluctuation width $\Delta \omega_{\mathrm{r}}{ }^{*}=$ $\left.0 \mathrm{~min}^{-1} \rightarrow \Delta \omega_{\mathrm{r}}{ }^{*}=300 \mathrm{~min}^{-1}\right)$. The rotational speed command $\omega_{\mathrm{r}}^{*}$ was $3000 \mathrm{~min}^{-1}$.

Table 1 shows the motor constant and control gain $\mathrm{K}_{\mathrm{s}}$ used in simulations. Furthermore, the load torque waveform was set as a sine wave, and the amplitude was set as $1 \mathrm{Nm}$.

Both figures show that the switches were conducted seamlessly, and stable control was possible even when suddenly changing from vibration suppression control to
Table 1. Motor constant and control gain (Ks)

\begin{tabular}{|c|c|}
\hline $\mathrm{Ke}$ & $0.2 \mathrm{Vpeak} /(\mathrm{rad} / \mathrm{s})$ \\
\hline $\mathrm{Ld}$ & $10 \mathrm{mH}$ \\
\hline $\mathrm{Lq}$ & $10 \mathrm{mH}$ \\
\hline $\mathrm{R}$ & $0.5 \Omega$ \\
\hline Poles & 4 \\
\hline $\mathrm{Jm}$ & $0.00038 \mathrm{~kg} \cdot \mathrm{m}^{2}$ \\
\hline $\mathrm{Ks}(\mathrm{S}$ controller 1$)$ & $879.2 \mathrm{rad} / \mathrm{s}$ \\
\hline $\mathrm{Ks}($ S controller 2$)$ & $1884 \mathrm{rad} / \mathrm{s}$ \\
\hline $\begin{array}{c}\text { Rotation speed } \\
\text { command }\end{array}$ & $3000 \mathrm{~min}^{-1}$ \\
\hline
\end{tabular}

high-efficiency control.

4.2 Time-expanded Waveform Figure 10 shows the time-expanded waveform $(3.8 \mathrm{~s}-3.9 \mathrm{~s}, 5.8 \mathrm{~s}-5.9 \mathrm{~s}, 7.8 \mathrm{~s}-7.9 \mathrm{~s}$, and $9.8 \mathrm{~s}-9.9 \mathrm{~s}$ ) of the waveforms shown in Fig. 8.

The waveform at $3.8 \mathrm{~s}-3.9 \mathrm{~s}$ in Fig. 10(a) was the operation at a vibration suppression control of $100 \%$, so the load torque and motor output torque were matched, and the rotational speed fluctuations were almost constant. However, the peak value of the motor current waveform was large. In contrast, the waveform at $9.8 \mathrm{~s}-9.9 \mathrm{~s}$ in Fig. 10(d) was the operation at a high-efficiency control of $100 \%$, so the motor output torque was constant, and the peak motor current value was also constant. However, in contrast to the waveform in Fig. 10(a), rotational speed fluctuations of $100 \mathrm{~min}^{-1}$ were generated.

Here, the rotational speed fluctuation width command value $\Delta \omega_{\mathrm{r}}{ }^{*}$ was $300 \mathrm{~min}^{-1}$, but the actual rotational speed fluctuations were $100 \mathrm{~min}^{-1}$. This signifies that the rotational speed fluctuation width only reaches a value of $100 \mathrm{~min}^{-1}$ when under load torque (amplitude $1 \mathrm{Nm}$ ) and a rotational speed of $3000 \mathrm{~min}^{-1}$ in this motor.

Figure 10(b) and Fig. 10(c) each show the operation waveforms according to each rotational speed fluctuation command value $\Delta \omega_{\mathrm{r}}{ }^{*}$. From the above, it can be seen that a seamless operation was possible.

\section{Experimental Results}

Figures 11 and 12 show vibration measurement results of the actual compressor. These results are experimental results using a single-cylinder rotary compressor. Here, Table 2 shows the motor constant and load torque waveform (estimated waveform) of the compressor used in experiments, and Table 3 shows the experimental conditions (compressor pressure conditions and rotational speed fluctuation width command value $\Delta \omega_{\mathrm{r}}^{*}$ ) in Fig. 12 .

Figure 11 shows the results of comparing the primary vibrations of the compressor where the vibration suppression control was at $100 \%$ (proposed method and conventional method $^{(17)}$ ) and when the vibration suppression control was absent (vibration value with no control is set as 1). The measured rotational speed was $1000 \mathrm{~min}^{-1}$. Results confirmed that a vibration reduction effect identical to the conventional method was obtained.

Figure 12 shows the experimental results of the compressor primary vibration when the rotational speed fluctuation command value $\Delta \omega_{\mathrm{r}}{ }^{*}$ was changed (vibration at $3000 \mathrm{~min}^{-1}$ was set as 1). Results confirmed the seamless control of the compressor vibration according to the rotational speed 


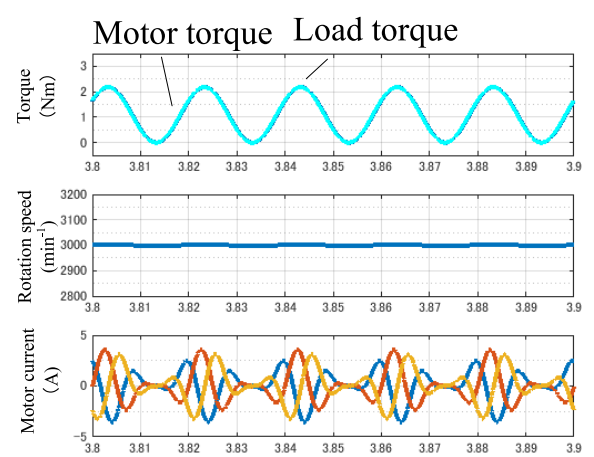

(a) Proposed seamless torque control

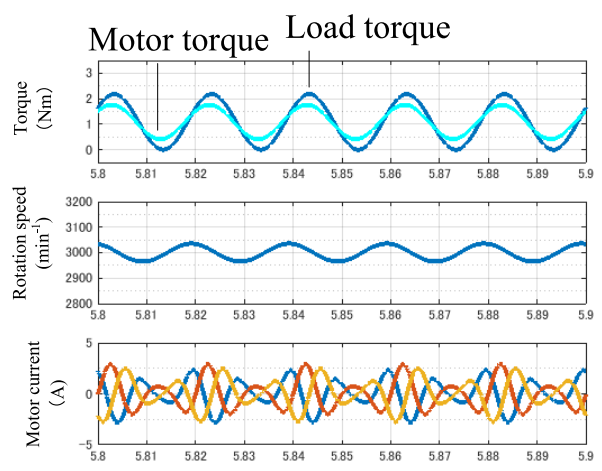

(b) Proposed seamless torque control
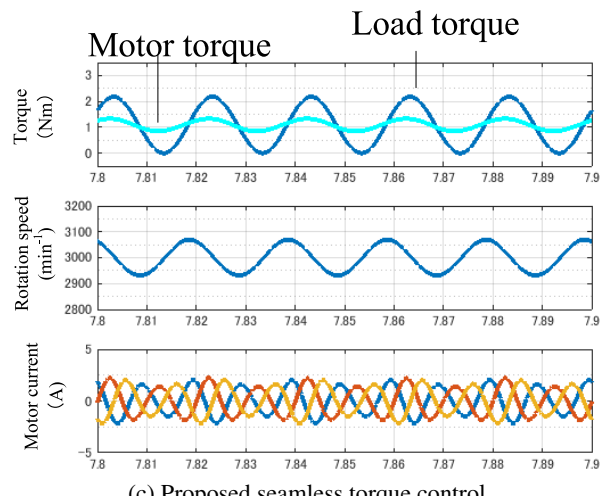

(c) Proposed seamless torque control
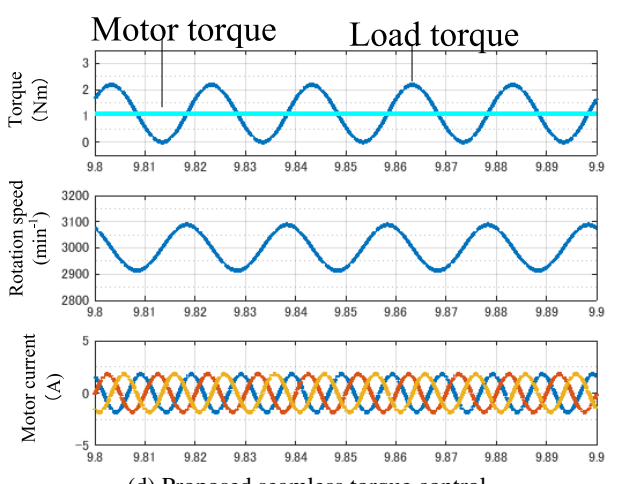

(d) Proposed seamless torque control

Fig. 10. Simulation waveform of seamless torque control at $3000 \mathrm{~min}^{-1}$ (time-expanded waveform)

fluctuation command value $\Delta \omega_{\mathrm{r}}{ }^{*}$. Here, the reason why the compression vibration did not become zero even below 1500 , when the rotational speed fluctuation command value $\Delta \omega_{\mathrm{r}}{ }^{*}$ was $0 \mathrm{~min}^{-1}$, was because the torque command value output by the $\mathrm{S}$ controller was a sine wave (motor output torque was sine wave), whereas the actual load torque was a waveform that included many high-frequency components, as shown in

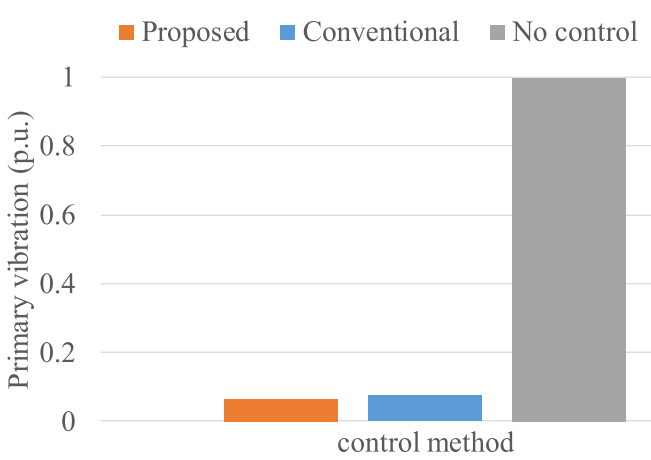

Fig. 11. Experimental results of compressor vibration suppression effect at $1000 \mathrm{~min}^{-1}$

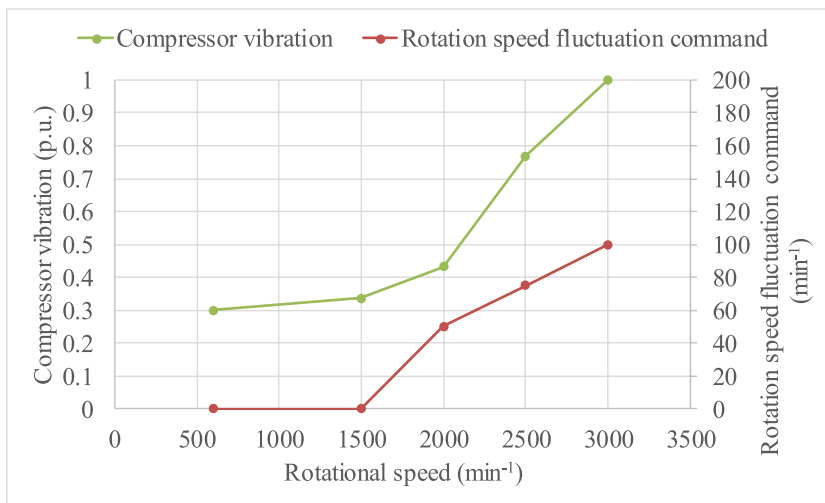

Fig. 12. Experimental results of compressor vibration in response to rotational speed fluctuation command

Table 2. Motor constant and load torque waveform at the time of experiment

\begin{tabular}{|c|c|}
\hline $\mathrm{Ke}$ & $0.18 \mathrm{Vpeak} /(\mathrm{rad} / \mathrm{s})$ \\
\hline $\mathrm{Ld}$ & $8.1 \mathrm{mH}$ \\
\hline $\mathrm{Lq}$ & $13.6 \mathrm{mH}$ \\
\hline $\mathrm{R}$ & $0.59 \Omega$ \\
\hline Poles & 4 \\
\hline $\mathrm{Jm}$ & $0.00038 \mathrm{~kg} \cdot \mathrm{m}^{2}$ \\
\hline $\begin{array}{c}\text { Load torque with } \\
\text { respect to mechanical } \\
\text { angle } \\
(\mathrm{Pd} / \mathrm{Ps}: 2.3 \mathrm{MPa} / 1.4 \mathrm{MPa})\end{array}$ & 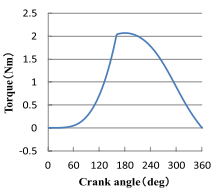 \\
\hline
\end{tabular}

Pd: Discharge pressure, Ps: Suction pressure

Table 2. Therefore, differences were present between the motor output torque and load torque, and the rotational speed fluctuation could not be controlled completely to $0 \mathrm{~min}^{-1}$.

In other words, further reductions in vibration require the addition of higher-order components of motor output torque (i.e., S controller corresponding to higher-order components).

\section{Conclusions}

In this paper, the $\mathrm{S}$ controller was used to propose a vibration suppression control which suppressed rotational speed fluctuations based on periodic torque resistance, as well as a control configuration which was capable of seamlessly 
Table 3. Experimental conditions for seamless torque control

\begin{tabular}{|c|c|c|}
\hline Rotational speed $\left(\mathrm{min}^{-1}\right)$ & $\mathrm{Pd} / \mathrm{Ps}(\mathrm{MPa})$ & $\Delta \omega \mathrm{r}^{*}\left(\mathrm{~min}^{-1}\right)$ \\
\hline 600 & $1.8 / 1.4$ & 0 \\
\hline 1000 & $2.3 / 1.35$ & 0 \\
\hline 2000 & $2.8 / 1.35$ & 50 \\
\hline 2500 & $3.0 / 1.25$ & 75 \\
\hline 3000 & $3.4 / 1.2$ & 100 \\
\hline \multicolumn{2}{|r|}{ Pd: Discharge pressure, Ps: Suction pressure }
\end{tabular}

changing high-efficiency control, which sets motor output torque at a constant level to improve system efficiency.

The validity of the proposed method was confirmed with simulations and actual devices. Suppression effects of vibration suppression control and increased efficiency can be freely changed by using this control.

\section{References}

( 1 ) K. Nagatake: "Motor/Inverter Technology for Home Appliances", Nikkan Kogyo Shimbun (2000) (in Japanese)

( 2 ) K. Sakamoto, et al.: "A Simplified Vector Control for Position Sensoless Permanent magnet Synchronous Motor Drives", Industrial Application Conference of IEEJ, No.248 (2001) (in Japanese)

( 3 ) Y. Kawabata, et al.: "Study of Control for Position Sensorless and Motor Current Sensorless Parmanent Magnet Syncronus Motor Drives", Industrial Application Conference of IEEJ, No.171 (2002) (in Japanese)

( 4 ) K. Sakamoto, et al.: "A New Position Sensorless Control of Permanent Magnet Synchronous Motor using Direct Position Error Estimation", Industrial Application Conference of IEEJ, No.97 (2000) (in Japanese)

( 5 ) K. Tobari, et al.: "Examination of the new vector control system of the permanent magnet synchronous motor for high-speed", Industrial Application Conference of IEEJ, No.130 (2003) (in Japanese)

( 6 ) Z. Chen, et al.: "Extended Electromotive Force observer for sensorless control of Salient-Pole Type Brushless DC Motor", Annual Meeting of IEEJ, No.1026 (1999) (in Japanese)

( 7 ) Y. Ikenobo: "Latest Technology Trends in Motors", Sharp Technical Report, No.82 (2002) (in Japanese)

( 8 ) S. Hatori, et al.: "Suppression Control Method of Vibration for PMSM Utilizing Repetitive Control with Auto-tuning Function and Fourier Transform", IEEJ Trans. IA, Vol.121, No.3 (2001) (in Japanese)

( 9 ) S. Hattori, et al.: "Reduction Control Method of Torque Vibration for Brushless DC Motor Utilizing Repetitive Control with Fourier Transform", Transactions of SICE, Vol.36, No.5 (2000) (in Japanese)

(10) T. Hanamoto, et al.: "Small Vibration Suppression Control of Brushless DC Motors with Periodical Disturbance", IEEJ Trans. IA, Vol.117, No.3 (1997) (in Japanese)

(11) S. Higuchi, et al.: "Reduction Control of Vibration of Induction Motor with Pulsating Load by Repetitive Control Utilizing Acceleration Sensor", IEEJ Trans. IA, Vol.117, No.3 (1997) (in Japanese)

(12) T. Fukumoto, et al.: " Reduction of Cyclic Speed Change and Current Waveform Distortion Using Band-pass Filters for Compressor PMSM Sine-wave Position Sensor-less Drives", The Papers of Joint Technical Meeting on SPC and IEA of IEEJ, SPC-06-97/IEA-06-20 (2006) (in Japanese)

(13) T. Endo, et al.: "Speed Control Method for Pulsating Load-Compatible Brushless DC Motor", Annual Meeting of IEEJ, No.676 (1987) (in Japanese)

(14) T. Endo, et al.: "Speed Control Method of Bbrushless DC Motor for Suppressing Vibration of Compressor", Technical Meeting on SPC of IEEJ, SPC88-63 (1988) (in Japanese)

(15) T. Endo, et al.: "Air Conditioner Compressor Vibration Suppression Control by Torque Control of Brushless DC Motor", Technical Meeting on IEA of IEEJ, IEA-90-1 (1990) (in Japanese)

(16) M. Nakamura, et al.: "Study on Vibration Reduction of a Rolling PistonType Compressor by Motor Torque Control", Transactions of JSME, Vol.56, No.527 (1990) (in Japanese)

(17) Y. Notohara, et al.: "Reduction Control Method of Periodic Torque Disturbance for Compressor", Industrial Application Conference of IEEJ, No.1-57 (2004) (in Japanese)
(18) M. Yabe: "Energy Saving Technology in Refrigerator Inverters", Motor Technology Symposium, D6-3-1-10 (2004) (in Japanese)

(19) S. Fukuda, et al.: "PIS Compensator Based Current Control for ThreePhase Utility Interface Converters", IEEJ Trans. IA, Vol.124, No.1 (2004) (in Japanese)

(20) S. Fukuda, et al.: "A Current Control Method for Active Filters Using Sinusoidal Internal Model”, IEEJ Trans. IA, Vol.120, No.12 (2000) (in Japanese)

Yasuo Notohara (Member) March 1981 Graduated from Fukuoka

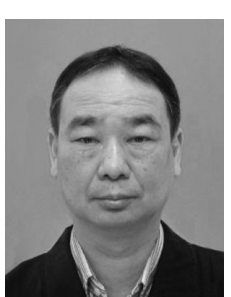
City Hakata Technical High School, Department of Electronics. He joined Hitachi Research Laboratories, Hitachi, Ltd. in April of the same year. Currently engaged in research and development of home appliance drive systems in the company's R\&D group. He received the 1997 Electrical Science and Engineering Encouragement Awards and 2005 The Japan Society of Mechanical Engineers Awards (Technology).

Dongsheng Li (Non-member) received the M.E. degree from Shang-

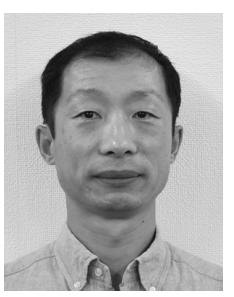
hai Jiaotong University in 1995 and the Ph.D. degree from Hokkaido University in 2004. From 1995 to 2000, he was with the Department of Information \& Control Engineering, Shanghai Jiaotong University, China. He is presently a senior researcher at Hitachi, Ltd. His research interests include powerfactor-correction techniques and PMSM control.

Yoshitaka Iwaji (Senior Member) Graduated from Ibaraki University

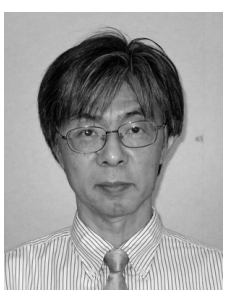
in March 1987 and completed the doctoral program at the Graduate School of Engineering, Hokkaido University in March 1992. He joined Hitachi, Ltd. in April of the same year and engaged in research on motor control in various fields such as drives for steel rolling mills, general industry, home appliances, automobile accessories, and railways. He received the 3rd Nagamori Award/Grand Prize of the Nagamori Foundation in 2017. Since April 2019, he has been appointed as a professor at the Department of Electrical and Electronic Systems Engineering, Graduate School of Science and Engineering, Ibaraki University. Ph.D. (Engineering).

Masahiro Tamura (Non-member) Graduated from Yamaguchi Uni-

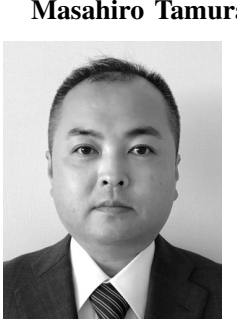
versity Graduate School of Science and Engineering in March 2002. He joined Hitachi Appliances, Inc. (currently Hitachi-Johnson Controls Air Conditioning, Inc.) in April of the same year. Mainly engaged in the development of compressor drive inverters and motor controls.

Koji Tsukii (Member) Graduated from the Graduate School of En-

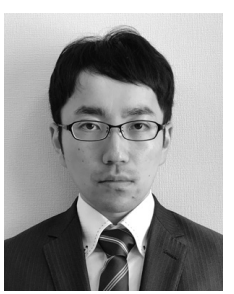
gineering, Faculty of Science and Technology, Meiji University in March 2009. He joined Hitachi Appliances, Inc. (currently Hitachi-Johnson Controls Air Conditioning, Inc.) in April of the same year. He mainly engaged in the development of compressor drive inverters and motor controls. 